\title{
Towards more sustainable work patterns
}

\author{
P. Blyton \\ ESRC Centre for Business Relationships, Accountability, \\ Sustainability and Society (BRASS), Cardiff University, Wales, UK
}

\begin{abstract}
Most discussions on sustainability and urban life ignore individuals as employees: any focus on work organisations tends to concentrate on the ways that those organisations interact with their external environments. However, a broader approach to sustainability raises the question of what more sustainable work lives in those settings would look like.

An analysis of the working patterns that currently typify most industrialised countries highlights a number of aspects in the arrangement of work schedules that need to be addressed to establish more sustainable long-term work patterns for the twenty-first century. Drawing on research on working time patterns and work flexibility, the background influences affecting current patterns are explored. This helps to identify, among other things, the potential obstacles to reforming extant work arrangements at a more accelerated pace than is currently evident.

A number of reforms to create more sustainable work arrangements are discussed, involving modifications both to the scheduling of work and also the location of work.
\end{abstract}

Keywords: work patterns, compressed workweeks, flexitime, homeworking, commuting, congestion.

\section{Introduction}

Most discussions on economic and social sustainability that refer to individual attitudes and behaviours ignore individuals as employees. Yet the way that people engage in, and experience paid work, particularly its location, and patterns of work arrangements and scheduling, has implications for sustainability. In turn, sustainability issues embedded in work arrangements can be viewed from both an individual sustainability view point (in relation to a successful balance between work and non-work life) and from a community 
view point. It is the latter aspect I want to comment on here (for discussion of the former, see for example Blyton et al. [3]; and Noon and Blyton [10]).

To explore these issues the remainder of the paper is divided into four further sections. In the following section I begin by identifying the aspects of work that have the most direct bearing on social sustainability discussions. These relate mainly to different aspects of work patterns. The next two sections then outline the current extent of the relevant work aspects, primarily drawing on recent UK evidence. What is apparent from this brief survey is the generally restricted nature of many aspects of work that could contribute to a more sustainable worksociety relationship. Thus in section 5 , some of the current obstacles to change are explored, together with certain recent developments that potentially will facilitate greater change in the future. A short concluding section gives some pointers to the further evidence needed to inform this agenda.

\section{Pattern of work and sustainability - some points of intersection}

Various aspects of paid work are relevant to sustainability discussions. These range from the location of that work - and the implications for the amount of travel required by individuals to engage in work - to whether the nature of the work undertaken contributes to, or detracts from, other sustainability efforts. Our attention here however is focused on the impact of different work patterns and work schedules, and of these two are particularly relevant:

- The number of days per week or month that individuals are required to travel to and from work

- The degree to which their work schedule requires travel within, or outside, congested rush-hour periods

In turn each of these has two elements relevant to our discussion

- The degree to which employees work compressed work week schedules or have the ability to work partly or wholly from home.

- The extent of flexitime arrangements, together with patterns of shiftwork and other non-standard work schedules

These aspects of work scheduling can have a significant bearing on both the extent and the timing of commuting from home to work; in turn these potentially have important implications for communities: in particular, the total amount of work-related commuting that takes place and the contribution of work schedules to congestion levels in particular locations. When, and how often employees need to travel to work will also have a bearing on public transport demand, levels of road congestion experienced, and in turn time spent in commuting and levels of pollution within communities en route.

\section{The evidence (i) the working week, compressed hours and working from home}

As is commonly known, the average working week for full-time workers fell substantially during the $20^{\text {th }}$ century in all industrialised countries. In the UK for 
example, a basic working week of around 54 hours at the start of the century had fallen to under 38 hours by 2006 (Blyton [2]). As part of this reduction the average number of days per week that full-time workers worked also fell with the widespread introduction of a 5-day work week in the 1960s, commonly as a result of a decline in Saturday working and the establishment of a non-work weekend. Since the 1960s however, further reductions in the basic working week have been introduced primarily by shortening the working day rather than by any further cutting of the number of weekly work days.

However, the number of work days has been reduced for a proportion of the full-time workforce. The arrangement of undertaking a full-time schedule in fewer than five days is commonly termed 'compression' or a compressed working week. Typically where this has been introduced it has taken the form of a 4-day week or 9-day fortnight (involving 4 days working one week, 5 the next) as well as a pattern of finishing work earlier on the $5^{\text {th }}$ day (although still involving 5 days' attendance).

In the UK in the most recent national workplace employment relations survey (WERS), compressed working hours were reported to be available to some employees in around one in six (16\%) of organisations (Kersley et al. [7] p. 250). One factor that has contributed to the availability of compression has been the spread of certain shiftworking systems, particularly the (re)introduction of 12-hour shift systems, most notably in continuous process operations (Spurgeon [12]). Where such a degree of compression is introduced, the additional days away from work, are generally highly valued by employees. A recent comparative study of one large group of workers moving to a 12-hour shift system and others remaining on 8 hours, for example, found that the 12-hour system attracted significantly greater satisfaction (Bacon et al. [1]). The main reason expressed for this satisfaction by those on the longer shifts was the greater number of free days that the system generated, with workers on 12 hours required to attend work 147 days per year, far fewer than their counterparts on 8 hour schedules. However, as the proportion of organisations offering compression to some of their employees indicates, this provision remains available to only a restricted minority of employees.

The number of days that employees need to travel to and from their workplace is influenced not only by the amount of compression built into their work pattern, but also any access they may have to spending part (or all) of their time working from home. Technological advances, particularly the facility for individuals to be connected electronically to their workplace via the internet and email, has increased the potential for more employees to undertake at least some of their work from home. Again however, despite the evident growth in this pattern of working in recent years it remains available to only a minority of employees. The WERS survey for example found that around one-quarter $(26 \%)$ of organisations indicated that working at or from home during normal work hours was available to at least some of their employees (Kersley et al. [7] p. 258). Among employees questioned as part of the same study, around 1 in 7 $(14 \%)$ indicated that they had (or believed they had) access to some degree of 
home working (ibid). Other studies have shown that this provision to undertake some work from home is more likely to be available to more senior employees (Tietze et al. [13]).

\section{The evidence (ii) flexitime and non-standard working hours}

A comparable picture is evident in terms of employees' access to flexibility over the time they can start and stop work. Typically such 'flexitime' systems involve a designated 'core' period when all employees are required to work, but with variability over the commencement and ending of work (for example a core of $10 \mathrm{am}-4 \mathrm{pm}$ with variable start-stop times between 7.30am and 10am, and $4 \mathrm{pm}$ to $6.30 \mathrm{pm})$. Within the EU as a whole, over half of such schemes in operation also allow employees to accumulate hours (by starting early and/or finishing late) to gain additional days off - thereby introducing a further small degree of compressed working (Lehndorff [8]). While some countries have extended this form of flexibility to a substantial proportion of their workforce (for example in larger organisations in Germany; see Croucher and Singe [4]), elsewhere its spread has been more restricted. In the UK for example, while access to flexitime has increased over the past decade, it remains available to only a minority of employees. The WERS study reports that just over one-third $(35 \%)$ of organisations have made flexitime available to some of their employees, (Kersley et al. [7]). The parallel survey of employees found similar results: $38 \%$ of employees reported access to flexitime (ibid, p.252). This is a significantly higher proportion than other surveys of work patterns have reported; however this discrepancy may be partly accounted for by the widespread use of informal time flexibility - ad hoc arrangements between workers and supervisors to accommodate particular circumstances in instances where formal flexitime arrangements are not available (see for example Marsh [9]). Among those with formal access to flexitime in the UK these are most likely to be working in non-manual occupations and in larger and public sector organisations, and in organisations where a high proportion of the workforce is female.

While flexitime is one means of altering standardised start and stop times, another is work schedules that introduce alternative patterns of work. These include shiftwork systems and different patterns of part-time working. In relation to shiftworking, a number of factors have led to a greater use of shift systems in recent times - in particular the extension of opening and operating hours in both service and manufacturing operations, and a desire to utilise shift systems rather than (usually more costly) overtime arrangements to cover the longer work period. An increased emphasis on availability of services such as retailing over a longer period - during the evenings and weekends for example, has led to an increased range of shiftwork schedules as organisations seek to cover both overall opening periods and times of greatest customer demand (notably lunchtimes and weekends) by using various shift and part-time arrangements. 


\section{Obstacles to accelerated change}

Overall, employee surveys that report attitudes to flexitime, compressed weekly hours and/or undertaking some work at home, report positive reactions among those with access to these arrangements. These work patterns are associated with a greater sense of autonomy, higher job satisfaction and job quality, and an improved feeling of work-life balance; employees with more control over their work patterns also typically report working more productively (Kelliher and Anderson [6]). The partial exception to this picture is the mixed response reported to those forms of compression that entail 12-hour night shifts. While these shifts generally attract premium payments and the compression creates valued additional days off, various negative consequences of the long night shifts are also widely reported, including increased health problems and added pressures on personal relationships (see for example, Shen and Dicker [11]). This response to long night shifts notwithstanding however, the overall employee response suggests that more employees would value greater access to flexitime, home-working and a degree of compression, were it to be made available

This begs the question of what possible obstacles stand in the way of a more accelerated diffusion of these work patterns? There are several potential sources of such obstacle. Statutory regulation of work and rest periods, for example, could act to limit the scope for compression of work hours. In practice, however, even where such working time regulations are in place - such as in the EU countries covered by the European Working Time Directive - ample scope exists for considerably more compression of working time than currently exists in most Member States (though regulation of night shift working is considerably tighter under the Directive, reflecting the health and safety concerns associated with night working) (Blyton [2]).

In the absence of constraints imposed by statutory regulation, it is more likely that it is a managerial unwillingness to extend further these forms of working. In part this may be a response to perceived operational requirements: the need for employees to be present to interact with customers and clients for example, rather than working from home. However, the breadth of organisations in which the more flexible work patterns currently operate, together with the considerable variation in their rate of developments in different countries, suggests a potentially much broader and deeper application than currently exists.

In addition to any perceived organisational constraints, management may resist these forms of working for other reasons. A number of studies have indicated potential managerial problems associated with compression, flexitime and home-working. A high level of compression, for example may raise concerns over work continuity and coordination. In the study of 8 and 12-hour working referred to above for example (Bacon et al. [1]) the agreed working week 9of 38 hours) resulted in those employees working 12-hour shifts (in blocks of four days) periodically being entitled to lengthy rest periods (up to 18 days) to bring their shift pattern into line with their contractual hours. In addition to some managers reporting such breaks as detrimental to familiarity with prevailing work issues, a degree of absenteeism immediately prior to the 
extended breaks exacerbated this problem further (ibid). Further, while long shift periods may reduce any coordination problems associated with shift handovers, the increased length of the shifts under the compressed system gave rise to increased problems for management seeking to cover for absences.

Other problems for management have been identified in relation to provision for employees to undertake some work from home. Some of these relate to increased difficulty of coordinating joint activities, meetings and so on when employees are working a variety of working from home arrangements. Problems may also extend beyond the homeworkers themselves. A recent study by Golden [5] for example points to the difficulties caused by homeworking for those in the work organisation to whom working from home was not available. Those without access to working from home experienced lower levels of job satisfaction and a decrease in their own flexibility as the need arose to accommodate extra workload arising from co-worker absence. In addition, homeworking has to overcome management attitudes relating to control of less visible workers and also maintaining an organisational culture or ethos where employees attend the workplace for a smaller proportion of their total work time than hitherto.

More generally, the very popularity among employees of schemes such as flexitime may militate against their widespread adoption insofar as once introduced, such schemes prove difficult for management to withdraw should circumstances change. In the case referred to above where part of the workforce moved to 12-hour shifts, many managers subsequently interviewed were keen to return to 8-hour shifts because of problems associated with the longer patters, but its popularity among the workforce created strong resistance to any return to the former system.

To a degree, we may anticipate some of these obstacles to compression, homeworking and flexitime diminishing in the coming period. The increase in flexitime in the UK since the 1990s signals a growing acceptance that this work pattern can be incorporated into a variety of organisational requirements (Kersley et al. [7]). Further, the continued growth of different part-time schedules, and the increased demand for work to be scheduled in the evenings and at weekends, are contributing to a further reduction in the notion of a 'standardised' and uniform work time pattern. Further, research evidence on any deleterious organisational effects (for example on co-workers) of allowing staff to work from home is significantly reduced if the practice involves relatively short rather than extended periods (Golden [5]). At the same time, a continuing managerial reluctance to extend such schemes will inhibit the extent to which they can contribute to a more sustainable pattern through reduced journeys to and from work and a greater availability of travelling outside rush-hour periods.

\section{Conclusions}

Potentially, greater use of flexitime, working from homer and compressed work weeks could contribute to more sustainable communities by reducing congestion and the number of journeys required to undertake paid work. Yet in each case 
these practices are not unproblematic for employees or those managing them. Compression could potentially increase fatigue levels, reduce continuity at work on days that employees are absent, and could cause non-work tensions where long (particularly night) shifts are involved. As well as the issues discussed for management, homeworking could also give rise to a heightened sense of employee isolation and invisibility within the organisation, which may in turn be associated with poorer promotion opportunities. Likewise, flexitime may create issues of staff (un)availability at times outside the nominated core period, as well as potentially requiring greater recording of periods worked - a more timeconsuming activity than where everyone begins and ends work at the same time.

What the problematic nature of these work practices underlines is the need for clearer evidence of the circumstances in which any negative outcomes are minimised. With the likely further expansion in opening and operating periods, the growth of less standardised work patterns looks set to continue. What is needed then is greater understanding of how best to introduce such changes in work practices that benefit not only the people and organisations involved but also the wider communities in which those organisations are situated.

\section{References}

[1] Bacon, N., Blyton, P., \& Dastmalchian, A., The significance of working time arrangements accompanying the introduction of teamworking: evidence from employees, British Journal of Industrial Relations, 43(4), pp. 681-701, 2005.

[2] Blyton, P., Working time and work-life balance, (Chapter 27) The Sage Handbook of Industrial Relations, eds. P. Blyton, N. Bacon, J. Fiorito \& E. Heery, Sage: London and California, pp. 513-28, 2008.

[3] Blyton, P., Blunsdon, B., Reed, K. \& Dastmalchian, A., eds Work-Life Integration, Palgrave Macmillan, Basingstoke, Hants, 2006.

[4] Croucher, R \& Singe, I., Co-determination and working time accounts in the German finance industry, Industrial Relations Journal, 35(2), pp. 15368, 2004.

[5] Golden, T., Co-workers who telework and the impact on those in the office: understanding the implications of virtual work for co-worker satisfaction and turnover intentions, Human Relations, 60, pp. 1641-68.

[6] Kelliher, C. \& Anderson, D., For better or for worse? An analysis of how flexible working practices influence employees' perceptions of job quality, International Journal of Human Resource Management, 19(3), pp.419-31, 2008.

[7] Kersley, B., Alpin, C., Forth, J., Bryson, A., Bewley, H., Dix, G. \& Oxenbridge, S., Inside the Workplace: Findings from the 2004 Employment Relations Survey, Routledge, London, 2006.

[8] Lehndorff, S., Flexibility and control: new challenges for working-time policy in the European Union, Labour and Industry, 17(3), pp.9-27, 2007.

[9] Marsh, C., Hours of Work of Men and Women in Britain, HMSO, London, 1991. 
[10] Noon, M. \& Blyton, P., The Realities of Work, $3^{\text {rd }}$ Edition, Palgrave Macmillan, Basingstoke, Hants.

[11] Shen, J. Dicker, B., The impacts of shiftwork on employees, International Journal of Human Resource Management, 19(2), 392-405.

[12] Spurgeon, A., Working Time: Its Impact on Safety and Health, International Labour Organization, Geneva, 2003.

[13] Tietze, S., Musson, G. \& Scurry, T., Improving services, balancing lives? A multiple stakeholder perspective on the work-life balance discourse, (Chapter 11)

[14] Work-Life Integration, P. Blyton, B. Blunsdon, K. Reed, \& A. Dastmalchian, eds Palgrave Macmillan, Basingstoke, Hants, pp. 180-95, 2006. 